\title{
Goal Integration and Well-Being
}

\section{Self-Regulation Through Inner Resources in the Netherlands and Spain}

\author{
Dirk van Dierendonck \\ Erasmus University, the Netherlands \\ Raquel Rodríguez-Carvajal \\ Bernardo Moreno-Jiménez \\ Autonomous University, Madrid, Spain \\ Maria T. M. Dijkstra \\ VU University, the Netherlands
}

\begin{abstract}
Personality integration has been related to individual well-being. The present study focused on the combined influence of personality integration through the personal-striving goal construct, active-passive approach toward achieving one's goals, and inner resources on wellbeing. Specific attention was given to how this process works out in two culturally different countries: the Netherlands and Spain. Results indicated that goal integration, passive thinking, active thinking, and vitality were higher in the Netherlands compared to Spain. It was also shown that inner resources combined with active thinking to function as a buffer for the possible negative effects on vitality. Results were similar in both countries, a finding that provides an indication for possible cross-cultural generalization of this process. The overall results present active-passive thinking combined with inner resources as an influential factor in the relation between goal integration and well-being.
\end{abstract}

Keywords: well-being; motivation; spirituality; goals

Dast research and theoretical developments have greatly advanced our understanding of I the potential benefits of personality integration for individual well-being (Allport, 1967; Deci \& Ryan, 1991). Indeed, it has been shown that measures of personality integration predict self-actualization, vitality, openness to experience, self-esteem, and subjective well-being (Sheldon \& Kasser, 1995). Personality integration can be defined as the extent to which aspects of one's personality cohere with one another (Sheldon \& Kasser, 1995). Given that goals are at the core of how we approach life (Karoly, 1999), goal integration is an essential element of personality integration. Goal integration occurs when a person's different goals cohere with one another. As reported by Sheldon and Emmons (1995), goal integration is associated with a more efficient progress toward goals because it allows for the use of more efficient planning. In the same line of argument, dissimilar goals require a number of plans and therefore put more pressure on limited resources, such as time, energy,

Authors' Note: Please address correspondence to Dirk van Dierendonck, RSM Erasmus University, P.O. Box 1738, 3000 DR Rotterdam, The Netherlands; e-mail: DvanDierendonck@rsm.nl 
or money. It is, therefore, likely that goal integration will be related not only to goal progress but also to well-being. The focus in this article is on gaining insight into personality integration by concentrating specifically on the relationship between goal integration and individual's well-being.

When studying this relationship, it should be recognized that individual differences due to cultural differentiation may play an important role. Individuals of different cultures may vary in their strategies to achieve goal integration (Matsumoto, 2006). As such, an important contribution of our study is the inclusion of the cross-cultural aspect by conducting the research in two different countries: the Netherlands and Spain. Previous studies have shown that the Netherlands and Spain are different cultures with respect to concepts included in our model. For example, multidimensional scaling of 36 countries puts the Netherlands and Spain on opposite sides of the axis that differentiates them on their level of, among others, extraversion, openness, power distance, and individualism (Allik \& McCrae, 2004). Another study showed that the culture of Spanish people is more honorbased, whereas the values of the Dutch are more individualistic (Fischer, Manstead, \& Rodriguez Mosquera, 1999). Furthermore, in the GLOBE leadership study of 62 countries, the Netherlands clustered together with other Germanic countries that use the German language, whereas Spain clustered together with other Latin countries that are directly influenced by Roman culture (Gupta \& Hanges, 2004). By including the Netherlands and Spain in our study, we can validate the theoretical model in two distinct European cultures and as such gain insight into a possible generalization of the results across different cultures.

After a failure to confirm the hypothesized relation between goal integration and wellbeing (Sheldon \& Kasser, 1995), no further attempts were made to study this topic. As such, we aim to further explore the relation between goal integration and well-being by considering the role of individual differences within this process. In other words, building on the work of Sheldon and Kasser (1995), we argue that a relation does exist. The strength of this relationship, however, will depend on how the possible negative impact of low goal integration is handled. More particularly, we propose that intentional mind sets and inner resources, an aspect of spirituality, influence this process, most notably in times of low goal integration.

The Sheldon-Kasser model builds on self-determination theory, in which choosing one's own direction in life is seen as crucial for well-being (Deci \& Ryan, 2000). Most empirical research on this theory has been done in the United States and Canada (Rudy, Sheldon, Awong, \& Hoon Tan, 2007). So this study with samples of countries outside of North America provides additional information on which aspects can be generalized across cultures and which aspects are specific for a particular culture.

\section{Goal Integration}

The model that guided our research is depicted in Figure 1. The basic premise of our model is that conscious human behavior is regulated by an individual's goals (e.g., Locke $\&$ Latham, 1984, 1990). Once a person chooses to attain a goal, three mechanisms combine to regulate performance. First, through the mechanism of goal direction, we are guided toward appropriate actions, as opposed to goal-irrelevant behavior. Second, by means of effort, people adjust to the difficulty level of the activity. Third, persistence causes people 
Figure 1

\section{Resource Model}

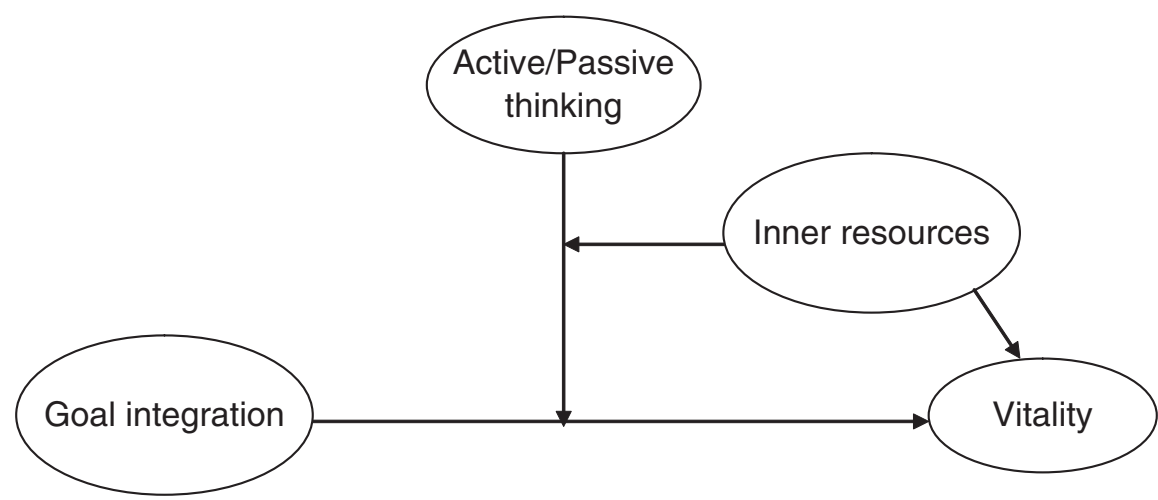

to slow down or work harder in the absence of time limits. Because of these mechanisms, goal methodology is considered a very useful approach to self-regulation research (Emmons, 2003; Karoly, 1999; Karoly \& Ruehlman, 1995; Latham \& Locke, 1991).

In their model, Sheldon and Kasser (1995) link goal integration with personality integration. Integration occurs when the aspects of one's personality in terms of personal goals cohere with one another and with personal needs. Based on this framework, we focus on horizontal goal coherence as one particular aspect of goal integration and personality integration. Coherence occurs when success on a particular goal a person strives for encourages success on another goal. We operationalized horizontal goal coherence with the personal-striving construct developed by Emmons (1986). This personal goals methodology was specifically designed to seize the self-regulation aspect of goals. Rather than focusing on broad, partly unconscious motives, personal goals allow a study of the mundane goals that drive daily behavior. As such, insights gained will have practical relevance because they can be translated into practical tools for coaching and training to teach people how to more effectively approach the goals in their daily life.

Cultural differences with respect to goal integration can be expected based on the clusters described by the Globe study (Gupta \& Hanges, 2004). The most relevant difference between the Germanic cluster (the Netherlands) and European Latin cluster (Spain) is the much stronger orientation on the future in the Germanic cluster. We therefore expect that the Dutch sample will experience more goal coherence and have a more active, less passive approach to achieving their goals.

\section{Well-Being}

Striving toward goals is related to well-being because it potentially provides for personal fulfillment (King \& Hicks, 2007). Well-being can be thought of as the way people feel about themselves and the settings in which they live and work. Therefore, well-being is associated with the quality of life and is generally looked upon as a broad area of scientific interest rather than a single specific construct (Kahn \& Juster, 2002). As a consequence, numerous related conceptions and components of well-being exist. In this article, 
we consider the well-being variable referred to as vitality, a specific psychological experience of possessing a subjective feeling of aliveness, enthusiasm, and positive energy (Ryan \& Frederick, 1997). Vitality is most relevant in this context because of its conceptual relationship to both psychological and physical well-being. In reviewing the literature, Ryan and Frederick (1997) discussed the theory of Freud (1923, 1924, in which the concept of energy was derived from Eros's life drives. Vitality is also given a central place in the Chinese concept of wellness (i.e., chi), in the experience of being free of repression as formulated by ego psychologists, and is seen as an indication of integration according to psychodynamic theorists. The importance of studying the sense of "energy," "engagement," and "vigor" that people experience was also emphasized for the work setting (Maslach \& Leiter, 1997; Schaufeli, Salanova, González-Romá, \& Bakker, 2002). People who experience more vitality also experience life as more autonomous and personally expressive (Ryan \& Frederick, 1997). As such, vitality is an indicator of eudemonic wellbeing, the experience that the activities in life are in accordance with deeply held values and needs (Waterman, 1993). From a goal perspective, vitality can be seen as the most relevant aspect of well-being because goals motivate people to do their best; they influence effort and persistence. They can induce people to work harder and longer (Latham \& Locke, 1991). Previous research showed that vitality was related to less distress, more positive and less negative feelings, and a better somatic functioning (Ryan \& Frederick, 1997). Evidently, the conclusion must be that vitality has emerged as an important wellbeing construct within diverse theoretical frameworks.

With regard to cross-national differences in well-being, the world database of happiness in nations (Veenhoven, 2007) ranks the Netherlands on Place 15-16 and Spain on Place 26-28 on the enjoyment of their life-as-a-whole. Given this higher level of happiness, we expect that the Dutch sample will also have higher values of vitality.

\section{Intentional Mind Sets}

Earlier studies showed no relation between goal integration and well-being outcome measures such as vitality (e.g., Sheldon \& Kasser, 1995). They argued that this might be because encouraging relations between goal strivings is only beneficial if the goals are pursued for autonomous reasons. In our study, we take a different perspective by proposing that the extent to which goal integration encourages vitality is related to a person's "intentional mind sets."

The process of self-regulation through goal integration is influenced by informationprocessing habits. These are states of readiness during the goal-striving process and are called "intentional mind sets" (Karoly, 1999). In general, intentional mind sets reflect distinct modes of selectively perceiving, framing, or schematizing goal-relevant behavioral episodes (Karoly, 1999) - in short, what we do when trying to achieve our goals. Concerning these intentional mind sets, Chaiken, Giner-Sorolla, and Chen (1996) emphasized the relevance of active (mindful and systematic) versus passive (heuristic) self-regulated processing while striving toward our goals. The significance of the active-passive discrimination is also reflected in motivational constructs, such as Elliot's (1997) theory of achievement motivation that differentiates between approach and avoidance goals. Previous studies showed that an active approach to goals is related to more well-being, whereas a passive 
approach was related to less well-being (Elliot \& Sheldon, 1998; Emmons \& Kaiser, 1996). In combining goal integration with passive and active mind sets, we can argue that an active approach - that is, a goal-directed activity initiated by the person-will be most important for a person's well-being in situations where different personal goals contradict each other (i.e., with a lack of goal integration). In other words, to circumvent the detrimental effects of striving toward goals that are not in line with each other, one should employ an active approach, meaning that actions are self-directed and according to plan. Therefore, we predict that the relationship between goal integration and well-being will be strengthened by higher levels of activity.

\section{Inner Resources}

The ability to control sudden impulses is essential in pursuing personal goals, but people often fail at exercising self-control, most particularly in times when there is a lack of goal integration. The limited strength model explains failure of self-control in terms of loss of energy or strength. Self-control is not a matter of strength (alone) but is strongly influenced by perceptual, cognitive, and motivational factors. This self-control can be viewed as a personal resource.

We introduce a specific personal resource that may be relevant in the self-regulation process of goal striving - that is, inner resources. Inner resources are defined as the inner aspects of a person that produce an individualized awareness of one's inner self and a sense of being part of a deeper spiritual dimension (Richardson Gibson \& Parker, 2003). Inner resources develop out of striving for wholeness and discovering one's identity and sense of empowerment (Howden, 1992). It is related to the view on spirituality as an inner resource or reservoir from which one can draw in times of need (Van Dierendonck \& Mohan, 2006). In this sense, inner resources give a feeling of strength when facing the challenges of dayto-day living.

In recent years, several studies have confirmed the beneficial impact of inner resources for an enhanced sense of well-being (Larson \& Larson, 2003). Inner resources may help to adopt a more confident and trustful attitude (Maton, 1989). It is also suggested that inner resources are instrumental in building resilience that helps to sustain the action to attain personal goals. Resilient people interpret their environment more positively and with less distrust (Semmer, 2003). In fact, more than any other resilience factor, inner resources are likely to be helpful in focusing the necessary attention, giving a feeling of strength (Pargament, 1997). People with inner resources have a greater acceptance for setbacks and failures and a greater trust that life can be positively influenced and will turn out for the best.

To understand inner resources as a spiritual nonspecific personal resource, it is important to realize that they presuppose a universal capacity through which strength and support can be uncovered. This focus on spirituality as an inner experience has been shown to have crosscultural construct validity across samples as diverse as Hindus, Christians, and Muslims (Piedmont \& Leach, 2002). The two Western samples included in our study both have a predominantly Christian background. Therefore, no differences in the experience of inner resources were expected.

Within our model, resilience through inner resources is most needed for persons who experience low goal integration. Therefore, in conditions of low goal integration, the ability 
to use inner resources will be most useful. As such, inner resources are hypothesized to enhance the positive effects of active thinking in conditions of low goal integration.

With respect to the process as a whole, there are some indirect indications for similarity between cultures. For example, Sheldon et al. (2004) reported that the extent people strive for goals because of intrinsic interest predicted well-being in four different cultures: the United States, Chinese, Taiwan, and South Korea. Similarly, among Japanese and Chinese samples, a more extrinsic academic motivation was related to less adjustment and performance, whereas intrinsic motivation was related to better adaptation (Rudy et al., 2007). These examples compared more individualistic with more collectivistic cultures and found more similarities than differences. Given that both our samples are from a European culture, we expected no significant differences in the process itself.

In sum, our study focuses on the combined influence of personality integration through the personal-striving goal construct (goal coherence), active-passive approach (intentional mind sets), and inner resources on well-being. Though several related studies on optimal psychological health do occur (e.g., Glen, Ryan, Manly, \& Deci, 1999; Sheldon \& Kasser, 1995) and the relevance of the different concepts in our model is sustained in previous studies, the relative influence of these concepts within one model has not yet been tested. Our model will be tested in two samples: one from the Netherlands and one from Spain. Hereby, we add a cross-cultural dimension to our study.

\section{Method}

\section{Participants}

Sample 1. Participants were 228 second-year Dutch undergraduate psychology students. The sample consisted of 128 men $(56.4 \%)$ and 100 women $(43.6 \%)$. The mean age was 21.2 years $(S D=7.6)$. The survey was administrated after a course. Participation was voluntary and anonymous, and no incentives were offered to the participants (response rate was $82.2 \%$ ).

Sample 2. The Spanish sample consisted of 114 second-year undergraduate psychology students. The survey was administrated as part of a course. All those who participated read and signed an information sheet indicating that participation was voluntary (response rate was $80.4 \%$ ). The Spanish sample consisted of 36 men $(31.6 \%)$ and 78 women $(68.4 \%)$. The mean age was 23.1 years $(S D=3.2)$.

\section{Measures}

We used an ideographic goal assessment technique (Emmons, 1999; Little, 1993) in which participants listed their personal strivings, defined as "the things that you typically or characteristically are trying to do in your everyday life." For both languages, two persons with an excellent command of the English language independently translated the measures into Spanish and Dutch. The different versions were back translated into English to asses which one most closely resembled the original version. After having been shown examples, participants were asked to list four strivings of their own that would last "at least 
through the next 3 to 6 months." Actual strivings listed by participants included "get good grades," "getting on well with parents," "lose weight," and "get to know more people." Now being aware of their specific (personally important) strivings, respondents were asked to answer the questions that followed.

Goal integration. Participants wrote their four strivings down the sides and across the top of a $4 \times 4$ matrix and rated each pair of strivings as to how much each striving supported or hindered them in achieving the other striving (similar to the coherence measure of Sheldon \& Kasser, 1995). The scale ranged from -2 (very harmful) to 2 (very helpful). A goal integration score was computed by summing the ratings. This method provides for a tailor-mate goal integration score because the scoring is directly in relation to the perceived significance of the specific goals of each individual. At the same time, it allows for a quantitative analysis of the process through which more or less goal integration is related to vitality, independent of different goal content (Emmons, 1999).

Intentional mind sets. Active and passive thinking were measured with a scale based on the intentional mind set framework formulated by Karoly (1999). The items were formulated by Karoly and sent to the first author (Karoly, personal communication, July 3, 2002) for use in research. Active thinking was measured with one item: "When working toward obtaining your goal, to what degree do you prefer to expend effort in thinking through and exploring all the possible alternative courses of action?" Passive thinking was also measured with one item: "When working on this goal, to what extent do you just let things happen rather than trying to anticipate events?" Each of the four personal goals was assessed with these two items on a scale that runs from 0 (not at all) to 7 (extremely). Cronbach's alpha for the Dutch and Spanish samples were .79 and .64, respectively, for active thinking and .80 and .74 , respectively, for passive thinking.

Inner resources. Inner resources was measured with the 6-item Inner Resources Scale developed by Van Dierendonck (2004). The scale asks respondents to indicate their level of occurrence using a 5-point Likert-type scale ranging from not at all to very much. Sample items include "I have inner strength," "I have experienced my own strength in times of struggle," and "I rely on inner strength in hard times." A reliability analysis of these items revealed good internal consistency $(\alpha=.80$ for the Dutch sample and $\alpha=.73$ for the Spanish sample).

Vitality. Vitality was measured with the seven items of the Subjective Vitality Scale (Ryan \& Frederick, 1997), ranging from 1 (not at all true) to 7 (very true). A sample item is "I feel energized." Reliability analyses revealed excellent consistency in both Dutch and Spanish samples, with a Cronbach's alpha of .84 and .82, respectively.

\section{Results}

The descriptive statistics of the study variables in the Dutch and Spanish samples are shown in Table 1. On the whole, the intercorrelations between the concepts are low, 
Table 1

Descriptive Statistics and Intercorrelations for Both Samples

\begin{tabular}{|c|c|c|c|c|c|c|}
\hline & $M$ & $S D$ & 1 & 2 & 3 & 4 \\
\hline \multicolumn{7}{|c|}{ Dutch sample $(n=228)$} \\
\hline 1. Goal integration & 2.23 & 1.89 & & & & \\
\hline 2. Active thinking & 17.96 & 6.88 & $.15^{*}$ & & & \\
\hline 3. Passive thinking & 14.82 & 7.00 & .04 & -.13 & & \\
\hline 4. Inner resources & 3.43 & 0.84 & $.15^{*}$ & $.22 * *$ & .01 & \\
\hline 5. Vitality & 5.03 & 1.09 & $.17 *$ & .04 & -.11 & $.14^{*}$ \\
\hline \multicolumn{7}{|c|}{ Spanish sample $(n=114)$} \\
\hline 1. Goal integration & 1.75 & 1.86 & & & & \\
\hline 2. Active thinking & 15.64 & 5.55 & .11 & & & \\
\hline 3. Passive thinking & 11.49 & 5.97 & -.01 & -.08 & & \\
\hline 4. Inner resources & 3.53 & 0.65 & .10 & $.19 *$ & .04 & \\
\hline 5. Vitality & 4.62 & 0.93 & .04 & .12 & -.01 & $.35^{* *}$ \\
\hline
\end{tabular}

${ }^{*} p<.05 .{ }^{* *} p<.01$.

suggesting independence of the constructs in the model. The only exception was the moderately strong correlation between vitality and inner resources in the Spanish sample. This is a limited confirmation of the interrelatedness of inner resources and vitality.

Before testing the differences in mean levels of the variables in our study, the construct equivalence was tested. The most commonly used technique within cross-cultural research is the proportionality coefficient, the Tucker's phi (Tucker, 1951). It tests to what extent the factor loadings of the items on the latent factor are invariant across groups. Values higher than .90 or .95 are usually taken to indicate factorial invariance (Van de Vijver \& Leung, 1997). The Tucker's phi in this study, comparing the Spanish and the Dutch samples, was excellent: goal integration (.99), active thinking (.94), passive thinking (.99), inner resources (.99) and vitality (.99). So we can conclude that the concepts were similarly experienced in both samples.

The next step was testing the mean differences between the samples. Using a multivariate MANOVA showed an overall significant effect, $F(5,318)=2,495.30, p<.001$, revealing that the Dutch experienced higher overall levels. This effect was qualified by univariate differences in four out of five variables: that is, goal integration, $F(1,322)=5.05, p=.025$, $R^{2}=.02$, passive thinking, $F(1,322)=20.75, p<.001, R^{2}=.06$, active thinking, $F(1,322)=$ $10.53, p=.001, R^{2}=.03$, and vitality, $F(1,322)=10.72, p=.001, R^{2}=.03$. No significant differences were found for inner resources, $F(1,322)=0.67, p=.413, R^{2}=.00$. These results were in accordance with expectations, with the exception of passive thinking, where the Dutch sample also scored higher.

The central focus of our model was on the interaction effects of goal coherence, activepassive mind set, and inner resources on vitality. Before testing the interactions, we analyzed the hypothesis of homocedasticity, independence, and collinearity. To explore the homocedasticity (homogeneity of variance), we looked at the scatter diagrams of standardized residuals against prognosticated standardized values, and they did not show any deviation in form. Furthermore, the selected models appear to be valid because these graphics did not show any 
Table 2

Hierarchical Multiple Regression of Coherence Active/Passive Thinking and Inner Resources on Vitality

\begin{tabular}{|c|c|c|c|c|c|c|}
\hline & \multicolumn{4}{|c|}{ Combined Sample } & \multirow{2}{*}{$\begin{array}{l}\text { Dutch } \\
\text { Sample }\end{array}$} & \multirow{2}{*}{$\begin{array}{l}\text { Spanisl } \\
\text { Sample }\end{array}$} \\
\hline & Step 1 & Step 2 & Step 3 & Step 4 & & \\
\hline \multicolumn{7}{|l|}{ Model summary $R^{2}$ change } \\
\hline 1 & $.03 * *$ & & & & & \\
\hline 2 & & $.07 * * *$ & & & $.07 * *$ & $.13^{* *}$ \\
\hline 3 & & & .01 & & .04 & .03 \\
\hline 4 & & & & $.03^{* *}$ & $.03 *$ & $.06^{*}$ \\
\hline \multicolumn{7}{|l|}{$\begin{array}{l}\text { Significant model, standardized } \\
\text { coefficients }\end{array}$} \\
\hline 1. Country & $.18^{* *}$ & $.20 * * *$ & $.20 * * *$ & $.19 * * *$ & & \\
\hline 2. Goal integration & & $.11^{*}$ & $.13^{* *}$ & $.17 * *$ & $.26^{* *}$ & $.14^{*}$ \\
\hline Active thinking (Actv) & & .00 & -.01 & .02 & -.02 & .08 \\
\hline Passive thinking (Passv) & & $-.09^{\dagger}$ & $-.10^{\dagger}$ & $-.09^{\dagger}$ & -.14 & .05 \\
\hline Inner resources (In Res) & & $.21 * * *$ & $.20 * * *$ & $.23 * * *$ & $.19^{* *}$ & $.36^{* *}$ \\
\hline 3. Goal Integration $\times$ Actv & & & -.07 & -.09 & -.07 & $-.18^{\dagger}$ \\
\hline Goal Integration $\times$ Passv & & & .00 & -.01 & -.06 & .02 \\
\hline Goal Integration $\times$ In Res & & & -.09 & -.08 & $-.14 \dagger$ & .05 \\
\hline In Res $\times$ Actv & & & .05 & .07 & .07 & .02 \\
\hline In Res $\times$ Passv & & & .03 & .05 & .14 & -.11 \\
\hline 4. Goal Integration $\times$ Actv $\times$ In Res & & & & $-.14 *$ & $-.18 *$ & $-.29 *$ \\
\hline Goal Integration $\times$ Passv $\times$ In Res & & & & $-.09^{\dagger}$ & $-.12^{\dagger}$ & $-.19^{\dagger}$ \\
\hline Adjusted $R^{2}$ & .03 & .09 & .09 & .11 & .10 & .13 \\
\hline
\end{tabular}

${ }^{\dagger} p>.010 .{ }^{*} p<.05 . * * p<.01 .{ }^{* * *} p<.001$.

regular shape. Independence was tested by the Durbin-Watson statistic, which uses residuals. The Durbin-Watson statistic should be between 1.5 and 2.5 for independent observations.

To detect any interaction effects, after entering the control variable, the independent variables were entered into the equation in three steps (cf., Aiken \& West, 1991). In each model, vitality served as the dependent variable. The first step involved the entry of goal integration, active and passive thinking, and inner resources. In the second step, the five two-way interaction terms between the four conceptual factors were entered. Finally, in Step 3, the two threeway interactions were entered. To avoid possible problems with multicollinearity, the variables were centered around zero before calculating their cross-product terms.

Table 2 shows the results of the hierarchical regression analyses in both samples. We started with testing the model by combining the samples into one composite sample. In the first step, therefore, country was entered to correct for different levels of vitality between the two countries. In the second step, the main effects were entered. This step was also significant due to the influence of goal integration and inner resources on vitality. In the third step, the two-way interactions were entered. These did not significantly add to the explained variance of vitality. The fourth step, consisting of the two three-way interactions, added significant extra variance to the model. The strongest three-way interaction was the one including active thinking. 
Next, we tested whether the pattern in the composite sample would be similar in the separate samples. The same regression analysis as just described was carried out, with exception of the inclusion of the country dummy variable. As is also shown in Table 2, the results are quite similar. As with regression analysis based on the composite sample, in the Dutch and the Spanish sample separately, the additional variance of the two-way interactions was not significant, whereas the three-way interactions were significant. In both samples, this effect was qualified by the three-way interaction of goal integration, active thinking, and inner resources. This lends credence to our hypothesis that the effects found with the combined samples were country independent. As a last check, hierarchical regression analysis was performed testing the possible interaction effect of country with inner resources, goal integration, and passive thinking and active thinking on vitality. Neither of the two-way interactions added significant variance to the main effects, $F(4,314)=1.84$, $p=.121$, nor did the three-way interactions add significant variance to the model, $F(6,308)=1.51, p=.173$, confirming our hypothesis.

The graphical depiction of the interaction of the results based on the combined samples is shown in Figure 2. The differences between the four slopes were tested with the formulas provided by Dawson and Richter (2006). The condition combining high active thinking with high inner resources is most noteworthy because the trend depicting the relation from goal integration to vitality is different from the other three slopes. A $t$ test showed that this slope is significantly different from the other slopes, $t(348)=4.299, p<.001 ; t(348)=$ $2.484, p=.013 ; t(348)=2.902, p=.004$, respectively. There are no significant differences among these three slopes, $t(348)=.511, p=.610 ; t(348)=.752, p=.452 ; t(348)=.477$, $p=.634$, respectively. Taken together, we can conclude that goal integration was related to more vitality, except when a person had both high inner resources and used active thinking in achieving goals. Here, the level of vitality remained very similar whether coherence was low or high, which confirms the hypothesized buffer effects of inner resources in conditions of low goal integration.

\section{Discussion}

This research was set up to investigate the interplay between personal resources and goalrelated self-regulation in relation to well-being. Specific attention was given to how this process would work out in two culturally different countries: the Netherlands and Spain. With regard to the differences between the countries, as expected, in the Netherlands, the level of vitality, goal integration, and active thinking was higher. This dovetails earlier studies on the differences between a Germanic country like the Netherlands and a Mediterranean Latino country like Spain. Surprising was the higher level of passive thinking in the Netherlands. It can be speculated whether a more active, future orientation will result not only in more goal integration and vitality but also in more consciously experiencing the mind set with which goals are approached, active and passive. More research would certainly be of interest here.

With respect to the process, the main finding was similar in both samples. Our results present active-passive thinking combined with inner resources as an influential factor in the relation between goal integration and well-being. It was shown that inner resources 


\section{Figure 2}

Interaction Between Goal Integration, Active Thinking, and Inner Resources on Vitality, Combined Sample
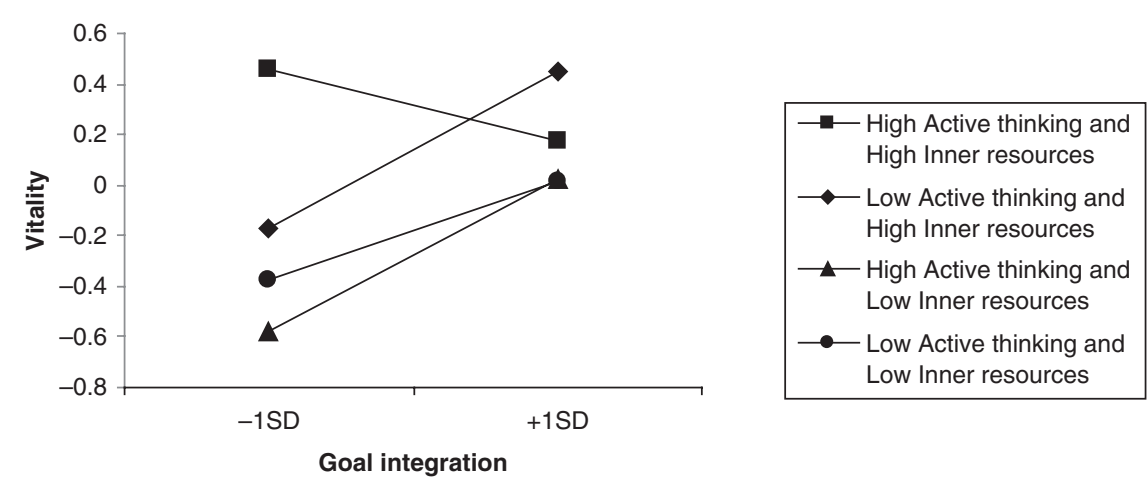

combined with active thinking function as a buffer for the possible negative effects on vitality of having goals that are not integrated. There were no significant interactions with country. This signifies that despite differences in mean levels, the combined influence of goal integration, self-regulation, and inner resources work out in a similar way across both samples. It should be noted that value differences between cultures like the Netherlands and Spain may influence the emotional experience as such (Fischer et al., 1999). However, ways of handling different levels of goal integration through active thinking, which is influenced by the available inner resources, seem to be quite similar across the cultures studied here. This dovetails earlier work of Sheldon et al. (2004), showing that cultural dimensions like the individualistic versus collectivistic dimension play a lesser role in determining goal-oriented, more intrinsically oriented processes. Given the central role played by inner resources, its spiritual aspect could be of importance here. Given the primarily Christian background of both samples, one could speculate how people from, for example, a Buddhist country (e.g., Thailand) would handle goal integration and self-regulation. Indications of possible different processes across East-West cultures can be found in a recent study on self-compassion, a construct based in Buddhist psychology (Neff, Pisitsungkagarn, \& Hiesh, 2008). The results from three samples from United States, Thailand, and Taiwan showed that self-compassion levels differed across cultures, with different relationships between self-compassion and well-being.

Understanding what factors determine whether people succeed or fail in achieving their goals is a fundamental concern in both basic and applied psychology. Recent evidence in the personal goals literature shows that the structure and organization of personality is an important determinant of health and well-being. For example, lack of personality integration (e.g., motive-goal incongruence, intragoal conflict) is a negative predictor of wellbeing, presumably because of its destructive effect on organismic need fulfillment (Brunstein, Schultheiss, \& Grassmann, 1998; Code \& Langan-Fox, 2001; Sheldon \& Elliot, 1998, 1999). Interestingly, despite differences in the mean levels between both samples of 
the concepts in this study, this process seems to be largely similar across both samples, suggesting a possible generalization across cultures.

Earlier studies have suggested but could not find confirmation that personality integration is related to more well-being. The significant three-way interaction in our study showed that the way people are influenced by more or less goal integration depends on people's mind set combined with their levels of inner resources. Low levels of goal integration can be related to less well-being if it is not handled well. Coping research has led researchers to advise people to take a rational, active approach when confronted with demanding situations (Quick, Quick, Nelson, \& Hurrell, 1997). The results of this study show that this holds specifically for people with high levels of inner resources. Particularly such people can, when confronted with low goal integration, deal with it by using an active mind set.

It can be speculated if this capacity to go within and use inner resources with active thinking has implications for the way personality integration is experienced. There is likely to be some form of detachment. Inner resources allow for a detached attitude, staying focused and letting things happen as they may, while at the same time working from an active mind set. Please note that inner resources are not the same as passive thinking, confirmed by the (almost) zero correlation with passive thinking and the positive correlation with active thinking (see Table 1). This sort of detachment brought on by inner resources signifies inner strength; the ability to stay calm and, as our results show, allow vitality to be experienced even though the circumstances are potentially stressful. This might signify that for circumstances such as low goal integration, inner resources are a source of strength and energy from which one can draw.

The limitations of this study must also be pointed out. First, our independent variables and outcome measures were based on self-reports. Self-report data can be contaminated by common method variance, as the dependent and independent variables are based on a single information source: the participants. Future research could profit from including additional measures, such as psycho-physiological variables. Second, the analyses in the current study are correlational and hence do not confirm causality. Furthermore, since the design of the study was cross-sectional, more complex forms of nonrecursive linkages could not be examined. Third, although our response rate was quite good when compared with other research using institutional populations and no incentives (Sudman \& Bradburn, 1988), the fact that we do not know whether responders differ from nonresponders may weaken the possibilities to generalize the results.

There are, nevertheless, several strong points that should not be overlooked. First, the results were found among two samples belonging to different countries with different cultures. The high values of the Tucker's phi, indicating construct equivalence across countries, strengthen a possible generalization of the results and enhance the external validity. Second, the most striking result is the three-way interaction where method variance does not play a role. One could argue, however, that the additional explained variance of the interaction effects was limited. Yet it has been shown that moderator analyses with hierarchical regression analysis are strongly attenuated by correlated error terms and that artificial interactions cannot be created (Chaplin, 1991; Evans, 1985). These and other studies warn against the very real possibility of Type 2 errors when trying to detect interaction effects. A rough rule suggested by Evans (1985) is to take 1\% of the explained 
variance as the criterion as to whether a significant effect exists. In our study, this criterion was met.

In conclusion, this study introduces the intriguing perspective that inner resources play an important role in the energy and vitality experienced by people while they try to achieve their personal goals, especially in times of conflicting goals. The results indicate that cross-culturally, comparing the Netherlands and Spain, the levels of vitality may be different but that the process that relates goal integration to vitality is quite similar across both cultures.

\section{References}

Aiken, L. S., \& West, S. G. (1991). Multiple regression: Testing and interpreting interactions. Newbury Park, CA: Sage.

Allik, J \& McCrae, R.R. (2004). Toward a geography of personality traits. Journal of Cross-Cultural Psychology, 35, 13-28.

Allport, G.W. \& Ross, J.W. (1967). Personal religious orientation and prejudice. Journal of Abnormal Psychology, 25, 3-33.

Brunstein, J. C., Schultheiss, O. C., \& Grassmann, R. (1998). Personal goals and emotional well-being. The moderating role of motive dispositions. Journal of Personality and Social Psychology, 75, 494-508.

Chaiken, S., Giner-Sorolla, R., \& Chen, S. (1996). Beyond accuracy: Defense and impression motives in heuristic and systematic information processing. In P. M. Gollwitzer \& J. A. Bargh (Eds.), The psychology of action: Linking cognition and motivation to behavior (pp. 553-578). New York: Guilford.

Chaplin, W. F. (1991). The next generation of moderator research in personality psychology. Journal of Personality, 59, 143-178.

Code, S., \& Langan-Fox, J. (2001). Motivation, cognitions and traits: Predicting occupational health, wellbeing and performance. Stress and Health, 17, 159-174.

Dawson, J. F. \& Richter, A. W. (2006). Probing three-way interactions in moderated multiple regression: Development and application of a slope difference test. Journal of Applied Psychology, 91, 917-926.

Deci, E. L., \& Ryan, R. M. (1991). A motivational approach to self: Integration in personality. In R. A. Dienstbier (Ed.), Nebraska symposium on motivation (pp. 237-288). Lincoln: University of Nebraska Press.

Deci, E. L., \& Ryan, R. M. (2000). The "what" and "why" of goal pursuits: Human needs and the selfdetermination of behavior. Psychological Inquiry, 11, 227-268.

Elliot, A. (1997). Integrating the "classic" and "contemporary" approaches to achievement motivation: A hierarchical model of achievement motivation. In M. Maehr \& P. Pintrich (Eds.), Advances in motivation and achievement (Vol. 10, pp. 243 -279), Greenwich, CT: JAI Press.

Elliot, A., \& Sheldon, K. (1998). Avoidance personal goals and the personality-illness relationship. Journal of Personality and Social Psychology, 75, 1282 -1299

Emmons, R. A. (1986). Personal strivings: An approach to personality and subjective well-being. Journal of Personality and Social Psychology, 51, 1058-1068.

Emmons, R. A. \& Kaiser, H. A. (1996). Goal orientation and emotional well-being: Linking goals and affect through the Self. In: L. L. Martin \& A. Tesser (Eds.) Strving and feeling: interactions among goals, affect, and self-regulation. (pp. 79-98). Mahwah, NJ: Lawrence Erlbaum Associates.

Emmons, R. A. (1999). The psychology of ultimate concerns: Motivation and spirituality in personality. New York: Guilford.

Emmons, R. A. (2003). Personal goals, life meaning, and virtue: Well springs of a positive life. In C. L. M. Keyes \& J. Haidt (Eds.), Flourishing: Positive psychology and the life well-lived (pp. 105-128). Washington, DC: American Psychological Association.

Evans, M. T. (1985). A Monte Carlo study of the effects of correlated method variance in moderated multiple regression analysis. Organizational Behavior and Human Decision Processes, 36, 305-323.

Fischer, A. H., Manstead, A. S. R., \& Rodriguez Mosquera, P. M. (1999). The role of honour-related vs. individualistic values in conceptualising pride, shame, and anger: Spanish and Dutch cultural prototypes. Cognition and Emotion, 13(2), 149-179. 
Freud, S. (1923). Das Ich Und Das Es. Leipzig, Vienna and Zurich: Internationaler Psycho-analytischer Verlag.

Freud. S. (1924). Der untergang des Ödipuskomplexes. Internationale Zeitschrift für Psychoanalyse, 10, 245-252.

Glen, N. A., Ryan, R. M., Manly, J. B., \& Deci, E. L. (1999). Revitalization through self-regulation: The effects of autonomous and controlled motivation on happiness and vitality. Journal of Experimental Social Psychology, 35(3), 266-284.

Gupta, V., \& Hanges, P. J. (2004). Regional and climate clustering of societal cultures. In R. J. House, P. J. Hanges, M. Javidan, P. W. Dorfman, \& V. Gupta (Eds.), Culture, leadership, and organizations. The GLOBE study of 62 societies (pp. 178-218). Thousand Oaks, CA: Sage.

Howden, J. W. (1992). Development and psychometric characteristics of the spirituality assessment scale. Unpublished dissertation, Denton, Texas.

Kahn, R., \& Juster, T. F. (2002). Well-being: Concepts and measures. Journal of Social Issues, 58, 627-644.

Karoly, P. (1999). A goal systems-self-regulatory perspective on personality, psychopathology, and change. Review of General Psychology, 3(4), 264-291.

Karoly, P., \& Ruehlman, L. S. (1995). Goal cognition and its clinical implications: Development and preliminary validation of four motivational assessment instruments. Assessment, 2(2), 113-129.

Kings, L. A., \& Hicks, J. A. (2007). Whatever happened to "What might have been"? American Psychologist, 62(2), 625-636.

Larson, D. B., \& Larson, S. S. (2003). Spirituality's potential relevance to physical and emotional health: A brief review of quantitative research. Journal of Psychology \& Theology, 31(1), 37-51.

Latham, G. P., \& Locke, E. A. (1991). Self-regulation through goal setting. Organizational Behavior and Human Decision Processes, 50, 212-247.

Little, B. R. (1993). Personal projects and the distributed self: Aspects of a conative psychology. In J. Suls (Ed.), The self in social perspective: Psychological perspectives on the self (Vol. 4, pp. 157-185). Hillsdale, NJ: Lawrence Erlbaum.

Locke, E. A., \& Latham, G. P. (1984). Goal setting: A motivational technique that works! Englewood Cliffs, NJ: Prentice Hall.

Locke, E. A., \& Latham, G. P. (1990). A theory of goal setting and task performance. Englewood Cliffs, NJ: Prentice Hall.

Maslach, C., \& Leiter, M. P. (1997). The truth about burnout: How organizations cause personal stress and what to do about it. San Francisco: Jossey-Bass.

Maton, K. I. (1989). The stress-buffering role of spiritual support: Cross-sectional and prospective investigations. Journal for the Scientific Study of Religion, 28(3), 310-323.

Matsumoto, D. (2006). Are cultural difference in emotion regulation mediated by personality traits? Journal of Cross-Cultural Psychology, 37, 421-437.

Neff, K. D., Pisitsungkagarn, K., \& Hiesh, Y.- P. (2008). Self-compassion and self-construal in the United States, Thailand, and Taiwan. Journal of Cross-Cultural Psychology, 39, 267-285.

Pargament, K. I. (1997). The psychology of religion and coping: Theory, research, practice. New York: Guilford.

Piedmont, R. L., \& Leach, M. M. (2002). Cross-cultural generalizability of the spiritual transcendence scale in India. Spirituality as a universal aspect of human experience. American Behavioral Scientist, 45, 1888-1901.

Quick, J. C., Quick, J. D., Nelson, D. L., \& Hurrell, Jr., J. J. (1997). Preventive stress management in organizations. Washington D.C: American Psychological Association.

Richardson Gibson, L. M., \& Parker, V. (2003). Inner resources as predictors of psychological well-being in middle-income African American breast cancer survivors. Cancer Control, 10, 52-59.

Rudy, D., Sheldon, K. M., Awong, T., \& Hoon Tan, H. (2007). Autonomy, culture, and well-being: The benefits of inclusive autonomy. Journal of Research in Personality, 41, 983-1007.

Ryan, R. M., \& Frederick, C. M. (1997). On energy, personality, and health: Subjective vitality as a dynamic reflection of well-being. Journal of Personality, 65, 529-565.

Schaufeli, W. B., Salanova, M., González-Romá, V., \& Bakker, A. B. (2002). The measurement of engagement and burnout: A two sample confirmatory factor analytic approach. Journal of Happiness Studies, 3(1), 71-92.

Semmer, N. K. (2003). Individual differences, work stress and health. In M. J. Schabracq, J. A. M. Winnbust, \& C. L. Cooper (Eds.), Handbook of work \& health psychology (2nd ed., pp. 83-120). West Sussex, UK: John Wiley \& Sons, Ltd. 
Sheldon, K. M., \& Elliot, A. J. (1998). Not all personal goals are "personal": Comparing autonomous and controlling goals on effort and attainment. Personality and Social Psychology Bulletin, 24, 546-557.

Sheldon, K. M., \& Elliot, A. J. (1999). Goal striving, need satisfaction, and longitudinal well-being: The selfconcordance model. Journal of Personality and Social Psychology, 76, 546-557.

Sheldon, K. M., Elliot, A. J., Ryan, R. M., Chirkov, V., Kim, Y., Wu, C., et al. (2004). Self-concordance and subjective well-being in four cultures. Journal of Cross-Cultural Psychology, 35, 209-223.

Sheldon, K. M., \& Emmons, R. A. (1995). Comparing differentiation and integration within personal goal systems. Personality and Individual Differences, 18(1), 39-46.

Sheldon, K. M., \& Kasser, T. (1995). Coherence and congruence: Two aspects of personality integration. Journal of Personality and Social Psychology, 68, 531-543.

Sudman, S., \& Bradburn, N. M. (1988). Asking questions: A practical guide to questionnaire design. San Francisco: Jossey-Bass.

Tucker, L. R. (1951). A method for synthesis of factor analysis studies (Personnel Research Section Report No. 984). Washington, DC: Department of the Army.

Van de Vijver, F. J. R., \& Leung, K. (1997). Methods and data analysis for cross-cultural research. In J. W. Berry, Y. H. Poortinga, \& J. Pandey (Eds.), Handbook of cross-cultural psychology (2nd ed., Vol. 1, pp. 257-300). Boston: Allyn and Bacon.

Van Dierendonck, D. (2004). The construct validity of Ryff's Scales of Psychological Well-Being and its extension with spiritual well-being. Personality and Individual Differences, 36, 629-643.

Van Dierendonck, D., \& Mohan, K. (2006). Some thoughts on spirituality and eudemonic well-being. Mental Health, Religion \& Culture, 9, 227-238.

Veenhoven, R., (2007). World Database of Happiness, Erasmus University Rotterdam.

Waterman, A.S. (1993). Two conceptions of Happiness: Contrast of personal expressiveness (Eudaimonia) and Hedonic Enjoyment. Journal of Personality and Social Psychology, 64, 678-691.

Dirk van Dierendonck is an associate professor of organizational behavior at the Rotterdam School of Management, Erasmus University. His research interests are servant-leadership and optimal human performance.

Raquel Rodríguez-Carvajal received her $\mathrm{PhD}$ from the Autonoma University of Madrid, Spain, and is an assistant professor of psychology at the Autonoma University. Her main research interests are in the areas of personality, emotional and cognitive regulation processes, and positive and health psychology in work settings.

Bernardo Moreno-Jiménez is an associate professor in the School of Psychology at the Autonoma University of Madrid. His main interests are focused on the personality and on the processes of health and disease.

Maria T. M. Dijkstra received her $\mathrm{PhD}$ in work and organizational psychology from the University of Amsterdam and is currently an assistant professor of organizational science at the VU University in Amsterdam. Her research interests include the relationship between conflict at work and individual and organizational outcomes. Within this area, she focuses on cognitive, emotional, and behavioral responses to workplace conflict.

For reprints and permissions queries, please visit SAGE's Web site at http://www.sagepub.com/journals Permissions.nav. 